\title{
THE IMPACT OF COVID-19 ON THE QUALITY OF HUMAN CAPITAL FOR THE ECONOMIC DEVELOPMENT OF AZERBAIJAN
}

\author{
Ali Aga Ismayilzade, Shafa Guliyeva, Vusala Teymurova, Reyhan Azizova \\ Azerbaijan State University of Economics (UNEC), Azerbaijan
}

Alishova Chinara

Institute of Economics of Azerbaijan National Academy of Sciences, Azerbaijan

\begin{abstract}
The study's purpose was to develop an approach to the empirical assessment of the impact of the quality of $\mathrm{HC}$ on the developing economy during the economic crisis, using the example of Azerbaijan. To obtain quantitative assessments of the qualitative characteristics of human capital development, the questionnaire method has been used. Based on a survey of 7232 people (which has been carried out in July-September 2017-2020 in the context of the economic regions of Azerbaijan) and the main components' method, the factors of the qualitative characteristics of the development of the HC were determined. An integral model of an empirical assessment of HC's qualitative development has been developed, and the nature and level of its influence on national economies during a pandemic have been determined. The findings can be critically useful in developing health and education policies and planning investments for post-crisis recovery.
\end{abstract}

Keywords: human capital, Azerbaijan, quality, economy, crisis, pandemic, COVID-19.

DOI: http://dx.doi.org/10.15549/jeecar.v8i1.639

\section{INTRODUCTION}

As a result of the spread of the pandemic of the coronavirus infection COVID-19, the trend in the development of the world economy is characterized by a recession, approaching depression, according to numerous economic forecasts, and which over the past 80 years has been recognized as one of the deepest economic shocks. Azerbaijan is no exception, the IMF predicted a recession in Azerbaijan's economy in 2020 at $2.2 \%$, and in the case of an optimistic scenario for the spread of a pandemic, Azerbaijan's GDP would grow by $0.7 \%$ in 2021 (International Monetary Fund, 2021). Simultaneously, the decline in world commodity prices directly affected Azerbaijan negatively due to a significant reduction in remittances, which exacerbated the negative consequences of what is happening in the country. The expected reduction in production by the end of the pandemic in Azerbaijan would be $3-3.5 \%$ (Organization for Economic Cooperation and Development, 2020). According 
to government officials, during the most severe quarantine measures, the Azerbaijani economy has lost 120-150 million Azerbaijani manats (70.7-88.4 million US dollars) per day (Organization for Economic Co-operation and Development, 2020). Moreover, it is expected that for 2020-2021 FDI, which has been an important source of economic growth and productive capacity in the country over the past decade, would decline by more than $30 \%$, which could exacerbate the country's potential postcrisis recovery (Organization for Economic Cooperation and Development, 2020). The recovery process could be too long, and the European Bank for Reconstruction and Development (EBRD) estimates that the national economy may continue to recover until 2025 (Williams, 2020).

The country's economic development's dynamism and inclusiveness play a key role in addressing the ambitious goals set in the Sustainable Development Agenda within its international commitments under the Paris Agreement on climate change and the Sustainable Development Goals (SDGs) (United Nations, 2021).

The fact that human capital's quality provides faster economic and social effects in times of crisis manifestations of economic development (Soyer, Ozgit \& Rjoub, 2020), it seems necessary to ensure a stable basis and achieve rapid and sustainable recovery of Azerbaijan's national economy's modern conditions. And it should be the centerpiece of efforts to tackle the immediate and long-term impact of the COVID19 pandemic on the country's economy and the health care system, education, and the general well-being of the population. It is an unconditional fact that Azerbaijan has made significant progress in the last decade to improve the qualitative and quantitative characteristics of human capital as a factor in its socio-economic development (Jaouani et al., 2020). However, in today's environment, the COVID-19 pandemic threatens to undo many of these gains as the government intensifies its efforts to support education and health services for the population against the backdrop of educational institutions and restrictions, what was imposed to protect public health (World Bank Group, 2020). Given the relevance of the problem, within the framework of this scientific study, an attempt was made to determine the fundamental components of human capital that help mitigate the negative impact on the economy of the pandemic's destructive factors in the example of Azerbaijan. The priority of their influence and possible forecast scenarios of economic development in the post-crisis period must also be substantiated, considering the country's level of human capital development.

\section{LITERATURE REVIEW}

Most scholars in the scientific literature agreed that the higher the human capital, the higher the people's wages and the country's income (Liu \& Yang, 2021), and the more cohesion in society (Carrasco \& Bilal, 2016). It is a fundamental driver of sustainable growth and poverty reduction (Park, 2018). In some studies, e.g., Gulaliyev et.al (2019), human capital is widely viewed as playing an essential role in the creation of wealth and economic growth.

Also, many scientists have studied and developed approaches to assessing the level of human capital in ensuring economic growth and potential, based on the allocation and substantiation of structural components, as well asindicators, universal methods for: assessing human capital (Liepè, 2016; Campbell \& Üngör, 2020; Wright, 2020); assessment of the relationship between human capital and economic growth (Lim et al., 2018; Hu, 2021; Zhou et al., 2018), income and employment levels (Liu \& Yang, 2021; Naval, Silva \& VázquezGrenno, 2020; Stauvermann \& Kumar, 2018), sustainability of economic development (Park, 2018), and the level of innovation ( $\mathrm{Hu}, 2021$; Park, 2018).

The disadvantages of methods for assessing human capital existing in the scientific literature include: : 1 ) are not characterized by complexity and in most cases were based on an assessment of the quantitative characteristics of human capital; 2) mainly were focused on assessing the human capital of the EU and China. Exceptions were indicators of human capital development of international organizations (World Bank Group, 2020; United Nations Development Program, 2020), which were published for most countries in the world. 
According to the most common methodology developed by the World Bank, the human capital indicator is calculated as an integral indicator based on specific indicators characterizing children's survival rate under 5 years of age: the expected number of years of schooling, adjusted for the quality of education; health (proportion of 15-year-olds living to age 60 , stunting rate among children under 5 years of age.) (World Bank Group, 2020). Despite the prevalence of this approach (Lim et al., 2018; Zhou et al., 2018; Perepelkin \& Perepelkina, 2018), its disadvantage is that it does not take into account the individual psychological component of human capital development and its qualitative characteristics, such as creativity, innovative activity, the level of intelligence, work endurance, adaptability to dynamic working conditions, etc.

Other specific indicators are characterizing the effectiveness of human capital, expressed through indicators of demography, education, environmental sustainability, gender, health, security, income, inequality, mobility, poverty, socio-economic sustainability, trade and financial flows, employment (United Nations Development Programme, 2020). But they, as in the previous methodology, do not allow assessing the individual psychological characteristics of the development of human capital and do not ensure the study's complexity since they are separate indicators that do not provide for an integral assessment.

In addition to various features in assessing the level of human capital, many scientific works have been devoted to considering crisis manifestations in the socio-economic system and the importance of human resources in stabilizing the economy (Soyer, Ozgit \& Rjoub, 2020; Thumiki, Jovancai-Stakić \& Al, 2019), neutralization of destructive factors of sustainable development. (Park, 2018). One of the most urgent tasks of researching economic crises has become an integral indicator that allows predicting periods of financial instability. One of the main factors is the level of human capital (Lusardi \& Mitchell, 2014). Based on the twentieth century's experience, structural crises occur every few decades (in the 1930s and 1970s) and lead to a radical restructuring of socio-economic and geopolitical balances, currency configurations, and economic paradigms (Semin et al., 2020; Megits, Neskorodieva \& Schuster, 2020). Each of the economic crises had its own characteristics. Human capital was one of the fundamental factors, where its quantitative and qualitative characteristics in ensuring the effectiveness of the anti-crisis strategy were more or less equivalent.

Together with financial, natural, and physical capital, human capital forms the basis of any country's national wealth (Lim et al., 2018). Consequently, the structure of its qualitative and quantitative characteristics and the dynamics of development have been historically determined by the national characteristics of the development of spiritual culture and civilization of certain peoples and states (Frankovský et al., 2019). Given this, to carry out the most reliable assessment of human capital, it is advisable to consider the national characteristics of its formation and characteristics. Among them, the social environment is of decisive importance. All things being equal, it is the foundation of human capital formation. As world practice shows, investments in a high-tech economy with a low intellectual culture level and a backward mentality do not give the expected results (Hu, 2021; Yasmin, El Refae \& Eletter, 2019; Bencsik et al., 2019).

Based on the above, within the framework of this study, an assessment of human capital was carried out, taking into account three aspects: the characteristics of the economic crisis, the qualitative characteristics of human capital, and the national characteristics of the country (in the example of Azerbaijan).

\section{METHODOLOGY}

The questionnaire method was used to obtain quantitative assessments of the qualitative characteristics of human capital development in Azerbaijan. The survey has been carried out in the context of 10 economic regions (Baku city, Apsheron, Ganja-Gazakh, Sheki-Zagatala, Lankaran, Guba-Khachmaz, Aran, KelbajarLachin, Gorno-Shirvan economic regions, Nakhchivan Autonomous Republic) for JulySeptember 2017-2020. Nagorno-Karabakh was not included in the study sample due to political 
instability and other non-economic factors affecting the development level. Human capital in the context of the study of the impact on economic development was as a factor of production (Lim et al., 2018). Therefore, a part of the working-age population took part in the survey: employed (including self-employed) persons and unemployed persons with a total number of 1,667 people, according to the results of the survey in 2017; 1,723 people in 2018; 1,837 in 2019; and 2,005 in 2020. The unemployed are not a factor of production at the moment, but they can become such a factor in the future, so they also took part in the survey. Simultaneously, students did not participate in the survey due to their high mobility and the impossibility of assigning them to a certain area (territorial discrepancy between the place of study and work).

As a percentage, the structure of respondents was $81.39 \%$ employed and $18.61 \%$ unemployed. The survey was carried out remotely via social networks and emails using Google Forms. Participation was voluntary and anonymous. To ensure the study's representativeness, the size of the sample should not be less than 384 people. at a significance level of 0.05 , which is determined using the equation (1) (Reid, 2015):

$S_{\text {min }}=\frac{D(p)^{2} \times v \times(1-v)}{\varepsilon^{2}}$,

where $S_{\min }$ - minimum requirements to the sufficiency of the sample population;

$D$ - standardized deviation at a confidence level $\pm 95 \%$;

$V$ - sample variation.

$\varepsilon$ - acceptable error rate.

The sample size of 1,667-2,005 people has ensured the representativeness of the survey results. Representativeness has also been evidenced by equal representation of respondents from all Azerbaijan economic regions; representation of the industry, agriculture, services, incl. financial, and different scales of activities of organizations (for the category of employed). During the survey, respondents were asked in the range of "1" - "5" points to assess their agreement with the approval of the questionnaire (https://docs.google.com/forms/d/1JCii9XSVNW 63o31pXefbiWsVnKy4DyRxJQGU-FR7gLs/edit). The higher the score, the higher the level of agreement with the statement.

The questions in the questionnaire were related to the level of manifestation of qualitative characteristics of human capital, such as creativity, initiative, innovative activity, adaptability, mobility, stress resistance, trust and solidarity with leadership, labor endurance, poise, striving for development, willpower, intelligence level, cognitive skills, a desire to work (Campbell \& Üngör, 2020; Naval, Silva \& Vázquez-Grenno, 2020; Wright, 2020). For statistical processing of the characteristics, the principal component method has been used in the Statistica 12.0 program. The analysis variables were the scores on the questionnaire, observations - respondents' answers without a breakdown by year and region. The principal components method was used in this study to measure the factors of the qualitative characteristics of human capital development. The Kaiser criterion determined the optimal number of factors (main components). The composition of these factors was formed based on the factor loadings of the point scores in the questionnaire questions. Factor loads $\geq 0.7$ were taken as significant (Menke, 2018). The advantage of using the values of factors in modeling compared with point estimates was that the points are correlated with each other, which makes it necessary to exclude some of the mutually correlated questions, leading to a decrease in the information content of the analysis. The use of factors allowed avoiding multicollinearity without reducing the information content.

The study assessed the impact of quantitative and qualitative indicators of human capital development on economic development. For this, one-factor linear regression models without an intercept have been built in Statistica 12.0.

When we assessed the impact of qualitative indicators, the dependent variable was the standardized annual values of the gross regional product per capita in Azerbaijan regions, expressed in manats (State Statistical 
Committee of the Republic of Azerbaijan, 2021). Independent variables were the average values of factors of qualitative characteristics of human capital development. The independent variables' values were calculated for each respondent for each year of the study as the sum of the standardized values of the scores for the questions that formed the corresponding factors, weighted by their coefficients of significance.

The arithmetic mean values of these factors for the respondents - representatives of each district separately for each study period - were used as independent variables. The COVID-19 pandemic has made significant adjustments to the country's socio-economic development. In this regard, to assess the impact of qualitative indicators of human capital development on economic development, two data sets (20172019 and 2020) were used to study possible changes during a pandemic. Thus, the sample for building models was 30 observations in the first and 10 in the second cases.

To build models for assessing the impact of quantitative indicators of human capital on the level of economic development, the independent variables were the standardized values of such indicators: population size (people); the number of births,; the number of deaths, people; population reproduction rate; the number of cases, people; the number of children in preschool institutions, people; the number of students in daytime general education institutions, people; the number of students in vocational education institutions, people; the number of students in universities, people; the number of students enrolled in the Ph.D. program, people; literacy rate (State Statistical Committee of the Republic of Azerbaijan, 2021).

The dependent variable was the standardized value of the volume of GDP per capita, expressed in manats (State Statistical Committee of the Republic of Azerbaijan, 2021). To build the models, we used annual data for the period 2000-2019. The number of observations was 20 periods. To build regression models, the values of indicators were used at the national level and not at the district level (as with a qualitative assessment) due to the lack of necessary statistical data in the regional context.
Regression models for quantitative and qualitative indicators of human capital have been built with the absence of a time lag and with a time lag. The strength of quantitative and qualitative indicators of human capital development was compared through indicators of elasticity according to the constructed regression models. Thus, the indicators that have a priority impact on economic development were determined and were selected as private indicators for assessing human capital. To calculate the integral indicator of human capital development, an equation has been developed:

$$
Q H C=\sum_{i=1}^{n}\left(\frac{E_{i}}{\sum_{i=1}^{n}\left|E_{i}\right|} \times H C_{i}\right)
$$

where $Q H C$ - integral indicator of human capital development;

$H C_{i}$ - the value of the private indicator of human capital - the value of the $i$-th factor of the qualitative characteristics of the development of human capital;

$E_{i}$ - the value of the average coefficient of elasticity of economic development (GRP per capita) from the $i$-th factor, \%;

$n$ - the number of significant factors in the qualitative characteristics of human capital development.

Equation (2) was proposed based on the fact that according to the study results, the priority influence on the economic development of the qualitative characteristics of human capital has been determined. The elasticity coefficients $(E I)$ were determined according to the constructed regression models and characterize the percentage change in the GRP per capita indicator with an increase in the value of the $i$ th factor of human capital development $(H C I)$ by $1 \%$.

\section{RESULTS}

The percentages of the variance of the factors that formed the qualitative characteristics of human capital development were determined based on a cumulative sample for 3 years, consisting of 7232 observations. Thus, the 
structure of the qualitative characteristics of human capital development was represented by the following factors: the factor of psychological stability, the development of cognitive skills, creativity, and innovative activity, initiative, the ability to develop, mobility, and adaptability.

The psychological stability factor, which explained $17.36 \%$ of the aggregate variance, assesses stress resistance, poise, the ability to control one's emotions, solidarity, and trust in leadership. This factor characterizes the effectiveness of cognitive and other skills from the position of the ability to abstract from the negative influence of the external environment, which causes psychological imbalance. The factor has been formed from the indicators HC_1, HC_6-HC_8, and HC_18-HC_21, corresponding to the questionnaire scores. Metrics legend were given in Google Form (https://docs.google.com/forms/d/

1JCii9XSVNW63o31pXefbi WsVnKy4DyRx JQGU-FR7gLs/edit).

The Factor of development of cognitive skills was formed from the indicators HC_2-HC_4 and HC_9-HC_11 and characterizes the level of intelligence, the ability to learn and apply knowledge in practice, the level of perception, representation, imagination. This factor, which explains the development of human capital by $17.16 \%$, serves as an objective basis for forming and developing other components of human capital.

The Factor of creativity and innovative activity, which includes indicators HC_5, HC_12, and HC_22-HC_25, determines the ability to generate ideas, find non-standard ways to solve problems, which, with the rational management of these abilities, allows to achieve the maximum economic effect at the micro and macro levels. The variance of the factor was $16.76 \%$.

The factor of initiative describes $15.96 \%$ of the variance. It reflects such characteristics of human capital that affect the efficiency of using this production factor, such as activity, energy, enterprise, initiative, determination, courage, and enthusiasm. The indicators that formed the factor were: HC_13, HC_14, HC_26, HC_27, HC_30, and HC_31.
The factor of the ability to develop characterizes the desire for self-development, constant self-improvement, and movement forward, the development of willpower, which, in the presence of an appropriate level of the above factors, contributes to an increase in labor productivity. The factor consists of indicators: HC_17, HC_28, and HC_32-HC_34, the variance of which was $14.26 \%$.

The factor of mobility and adaptability assesses the ability to adapt to new life conditions, work, the ability to change the type of activity, and switch to another task. Mobility and adaptability ensure the universality of human capital - the ability to work under different conditions. The variance of the factor was $8.46 \%$. The indicators that formed the factor were: HC_15, HC_16, and HC_29.

The adequacy of the factor analysis was evidenced by the sufficiency of the sample (the number of observations is more than 2 times higher than the number of variables corresponding to the scores in the questionnaire) and the cumulative percentage of the variance of deterministic factors $(89.96 \%$, which exceeds the accepted level of $80 \%$ (Menke, 2018)).

For the economic interpretation of the results obtained and determining the development of human capital's qualitative characteristics, the factors' calculated values were compared with the potential (maximum possible) ones (Table 1).

Despite the different categories of respondents (employed and unemployed), the values of factors within one economic region are low-variable. The coefficient of variation does not exceed $10 \%$. In this regard, Table 1 shows the average for the regions for a certain period, and the percent deviation of the actual values of the factors from the potential. The indicated percentages are interpreted as the corresponding lag of the factors' actual values from the maximum possible level of development of the qualitative characteristics of human capital. 
Table 1: Values of factors of qualitative characteristics of human capital development in Azerbaijan, for 2017-2020 in the context of economic regions (\% deviation of the actual values of factors from the potential)

\begin{tabular}{|c|c|c|c|c|c|c|c|c|c|c|c|c|}
\hline \multirow{3}{*}{ Economic region } & \multicolumn{12}{|c|}{ Factors } \\
\hline & Stab & $\operatorname{Cog}$ & Creat & Init & Dev & Mob & Stab & $\operatorname{Cog}$ & Creat & Init & Dev & Mob \\
\hline & \multicolumn{6}{|c|}{2017} & \multicolumn{6}{|c|}{2018} \\
\hline Baku city & 18.9 & 17.3 & 33.4 & 31.7 & 26.5 & 13.3 & 20.4 & 14.9 & 32.8 & 31.5 & 25.7 & 12.5 \\
\hline Absheron & 21.8 & 19.9 & 38.9 & 36.7 & 31.8 & 17.0 & 21.2 & 17.7 & 38.1 & 35.9 & 30.6 & 16.0 \\
\hline Ganja-Gazakh & 24.4 & 21.3 & 42.6 & 41.1 & 34.1 & 19.3 & 24.0 & 20.7 & 42.4 & 40.2 & 33.3 & 18.2 \\
\hline Sheki-Zagatala & 26.3 & 21.9 & 43.4 & 41.7 & 36.1 & 20.7 & 25.9 & 21.5 & 42.4 & 41.3 & 35.5 & 20.5 \\
\hline Lankaran & 26.3 & 22.3 & 44.3 & 42.3 & 38.0 & 21.9 & 26.1 & 22.1 & 43.9 & 41.9 & 37.4 & 21.1 \\
\hline Guba-Khachmaz & 23.0 & 20.5 & 41.8 & 38.4 & 35.1 & 18.2 & 22.4 & 19.9 & 40.8 & 38.0 & 34.5 & 16.8 \\
\hline Aransky & 22.6 & 20.1 & 41.2 & 38.4 & 34.3 & 17.8 & 22.4 & 19.3 & 40.8 & 38.8 & 34.1 & 16.2 \\
\hline Kelbajar-Lachinsky & 27.9 & 26.8 & 46.9 & 44.8 & 40.2 & 24.8 & 27.1 & 26.8 & 46.7 & 44.2 & 39.6 & 24.8 \\
\hline Gorno-Shirvan & 25.5 & 20.5 & 43.0 & 41.1 & 35.5 & 20.1 & 25.1 & 20.3 & 42.8 & 40.7 & 34.7 & 19.9 \\
\hline $\begin{array}{l}\text { Nakhchivan } \\
\text { Autonomous } \\
\text { Republic }\end{array}$ & 20.4 & 19.1 & 38.3 & 34.9 & 30.0 & 15.8 & 20.0 & 16.9 & 37.3 & 34.4 & 28.5 & 15.2 \\
\hline \multirow{3}{*}{ Economic region } & \multicolumn{12}{|c|}{ Factors } \\
\hline & Stab & $\operatorname{Cog}$ & Creat & Init & Dev & Mob & Stab & $\operatorname{Cog}$ & Creat & Init & Dev & Mob \\
\hline & \multicolumn{6}{|c|}{2019} & \multicolumn{6}{|c|}{2020} \\
\hline Baku city & 19.3 & 12.1 & 31.6 & 30.9 & 24.0 & 11.5 & 29.7 & 11.3 & 30.1 & 29.9 & 24.4 & 17.6 \\
\hline Absheron & 19.3 & 15.9 & 37.9 & 35.3 & 30.0 & 14.5 & 31.2 & 15.3 & 36.9 & 33.4 & 30.0 & 15.8 \\
\hline Ganja-Gazakh & 23.2 & 19.7 & 41.8 & 39.8 & 33.1 & 17.6 & 33.8 & 18.9 & 40.4 & 39.0 & 32.4 & 22.1 \\
\hline Sheki-Zagatala & 26.1 & 21.3 & 42.8 & 40.7 & 35.1 & 20.9 & 35.2 & 21.1 & 42.0 & 39.6 & 34.9 & 22.1 \\
\hline Lankaran & 25.7 & 21.5 & 43.0 & 41.5 & 36.3 & 20.5 & 36.0 & 21.3 & 42.4 & 41.1 & 35.7 & 26.0 \\
\hline Guba-Khachmaz & 21.6 & 18.7 & 39.3 & 35.9 & 33.3 & 15.4 & 31.8 & 17.5 & 38.9 & 34.0 & 33.1 & 18.2 \\
\hline Aransky & 22.6 & 17.9 & 39.8 & 38.6 & 33.5 & 16.0 & 31.6 & 17.5 & 38.7 & 36.1 & 33.3 & 17.8 \\
\hline Kelbajar-Lachinsky & 26.5 & 26.2 & 46.5 & 43.8 & 39.4 & 24.6 & 37.9 & 26.0 & 45.9 & 43.4 & 38.8 & 48.4 \\
\hline Gorno-Shirvan & 24.4 & 19.7 & 42.4 & 39.8 & 34.1 & 19.9 & 33.2 & 19.1 & 41.4 & 39.6 & 33.7 & 25.4 \\
\hline $\begin{array}{l}\text { Nakhchivan } \\
\text { Autonomous } \\
\text { Republic }\end{array}$ & 20.2 & 16.1 & 36.9 & 34.9 & 28.5 & 14.1 & 31.8 & 15.7 & 36.1 & 33.6 & 29.0 & 16.4 \\
\hline
\end{tabular}

Legend:

- Stab - psychological stability factor;

- $\quad$ Cog is a factor in the development of cognitive skills;

- Creat - the factor of creativity and innovative activity; 
- Init - initiative factor;

- Dev - the factor of the ability to develop;

- Mob - the factor of mobility and adaptability.

According to the estimates obtained, the highest level of development of human capital's qualitative characteristics was observed in Baku. In terms of factors, the smallest gap was with the potential level for the factor of mobility and adaptability (11.5-17.6\% during 2017-2020), and the factor for the development of cognitive skills (11.3-17.3\%). A similar situation is observed in other economic regions, for which these factors are the most developed. The largest gap between actual and potential values in all districts is observed for creativity and innovative activity (30.1-46.5\%) and the factor of initiative (29.9-44.8\%). For such regions as Kelbajar-Lachinsky, Lenkoransky, ShekiZagatalsky, Gorno-Shirvan, these factors are developed slightly more than half, which serves as the main limiting factor in the socioeconomic development of the regions due to the development of human capital.

During 2017-2019. the general dynamics of reducing the gaps between the actual and potential values of the qualitative characteristics of the development of human capital are traced. In 2020, for the development of cognitive skills, creativity, and innovative activity, initiative, and the ability to develop, these dynamics remained. The most significant impact of the COVID-19 pandemic was on developing the factor of creativity and innovative activity, and the factor of initiative, the values of which, in 2020 compared to 2019, on average in the country increased by $1.54 \%$ and $1.84 \%$, respectively. The development of these factors is due to unfavorable business conditions and job cuts, which stimulated the search for alternative survival ways. The development of the factor of psychological stability in connection with the pandemic decreased by $13.39 \%$, and the factors of mobility and adaptability by $6.66 \%$. The reasons for the decrease in factors are psychological tension associated with a threat to health and the threat of loss of income, a decrease in the number of alternatives for employment and business development resulting from the bankruptcy of business entities, and legal restrictions on some types of activity.

The values of the factors which are indicated in Table. 1, in the context of regions, are used as independent variables of regression models of the influence of the qualitative characteristics of human capital development on the level of economic development. The statistical significance of the models was assessed by the $F$ and t-test (Table 2).

Table 2: Regression models of the influence of the qualitative characteristics of human capital development on the region's economic development in Azerbaijan for the period 2017-2020

\begin{tabular}{|c|c|c|c|c|c|c|}
\hline \multirow{3}{*}{$\begin{array}{l}\text { Influence } \\
\text { factor }\end{array}$} & \multirow{3}{*}{ Influence model } & \multicolumn{4}{|c|}{ Model adequacy indicators } & \multirow{3}{*}{$\begin{array}{l}\text { Elasticity } \\
\text { index } \\
\text { value,\% }\end{array}$} \\
\hline & & \multicolumn{2}{|l|}{ F-test } & \multicolumn{2}{|c|}{ t-test } & \\
\hline & & Emp & Tab & Emp & Tab & \\
\hline \multicolumn{7}{|c|}{ Pre-crisis period (2017-2019) } \\
\hline Stab & $\mathrm{GRP}=0.2326 \times \operatorname{Stab}(-1)$ & 19.44 & 4.38 & 4.55 & 2.09 & 0.58 \\
\hline $\operatorname{Cog}$ & $\mathrm{GRP}=0.4674 \times \operatorname{Cog}(-1)$ & 17.82 & 4.38 & 6.90 & 2.09 & 2.22 \\
\hline Creat & $\mathrm{GRP}=0.4701 \times$ Creat $(-2)$ & 34.83 & 5.12 & 5.22 & 2.26 & 1.06 \\
\hline Init & $\mathrm{GRP}=0.4406 \times \operatorname{Init}(-2)$ & 21.32 & 5.12 & 5.62 & 2.26 & 1.55 \\
\hline Dev & $\mathrm{GRP}=0.4996 \times \operatorname{Dev}(-2)$ & 21.34 & 5.12 & 5.62 & 2.26 & 1.49 \\
\hline Mob & $\mathrm{GRP}=0.4958 \times \operatorname{Mob}(-2)$ & 12.57 & 5.12 & 5.41 & 2.26 & 1.18 \\
\hline
\end{tabular}




\begin{tabular}{|l|l|l|l|l|l|l|}
\hline \multicolumn{2}{|l|}{ COVID-19 pandemic period (2020) } & \multicolumn{5}{c|}{ Table 2: Continued } \\
\hline Stab & GRP $=0.4368 \times \operatorname{Stab}(-1)$ & 42.13 & 5.32 & 5.12 & 2.31 & 1.09 \\
\hline Cog & GRP $=0.8024 \times \operatorname{Cog}(-1)$ & 34.41 & 5.32 & 7.51 & 2.31 & 3.81 \\
\hline Creat & GRP $=0.9390 \times \operatorname{Creat}(-2)$ & 39.10 & 5.32 & 6.11 & 2.31 & 2.11 \\
\hline Init & GRP $=0.8348 \times \operatorname{Init}(-2)$ & 16.83 & 5.32 & 7.24 & 2.31 & 2.94 \\
\hline Dev & GRP $=0.8798 \times \operatorname{Dev}(-2)$ & 30.18 & 5.32 & 7.01 & 2.31 & 2.62 \\
\hline Mob & GRP $=0.8407 \times \operatorname{Mob}(-2)$ & 21.14 & 5.32 & 5.83 & 2.31 & 1.99 \\
\hline
\end{tabular}

Legend:

- Emp is the empirical value of the criterion;

- $T a b$ is the tabular value of the criterion at a significance level of $\mathrm{p}=0.05$;

- $\quad G R P$ is the standardized value of the GRP per capita indicator;

- Stab-Mob - the values of the relevant factors of human capital development's qualitative characteristics, taking into account the lag indicated in brackets.

The empirical values of the F-test and t-test exceed the tabular values at a significance level of $\mathrm{p}=0.05$, which indicates the statistical significance of the constructed models, the significance of independent variables. This indicates a significant influence of the qualitative characteristics of human capital development on the region's economic development.

Table 3: Regression models of the influence of quantitative indicators of human capital development on Azerbaijan's economic development for the period 2000-2019

\begin{tabular}{|c|c|c|c|c|c|c|}
\hline \multirow{3}{*}{$\begin{array}{l}\text { Independent } \\
\text { variable }\end{array}$} & \multirow{3}{*}{ Influence model } & \multicolumn{4}{|c|}{ Model adequacy indicators } & \multirow{3}{*}{$\begin{array}{l}\text { Elasticity index } \\
\text { value,\% }\end{array}$} \\
\hline & & \multicolumn{2}{|l|}{ F-test } & \multicolumn{2}{|l|}{ t-test } & \\
\hline & & Emp & Tab & Emp & Tab & \\
\hline Pop & $\mathrm{GDP}=0.4842 \times \operatorname{Pop}(-1)$ & 6.32 & 4.45 & 2.50 & 2.11 & 0.19 \\
\hline Birth & $\mathrm{GDP}=0.0572 \times \operatorname{Birth}(-7)$ & $4.41^{*}$ & 4.84 & $2.13^{*}$ & 2.20 & 0.01 \\
\hline Death & GDP $=-0.2761 \times$ Death $(-1)$ & 5.69 & 4.45 & -2.23 & 2.11 & -0.10 \\
\hline Rep & $\mathrm{GDP}=0.3351 \times \operatorname{Rep}(-1)$ & 5.90 & 4.45 & 2.36 & 2.11 & 0.14 \\
\hline Sick & GDP $=-0.5485 \times \operatorname{Sick}(-1)$ & 6.59 & 4.45 & -2.74 & 2.11 & -0.27 \\
\hline Presch & $\mathrm{GDP}=0.0047 \times$ Presch $(-6)$ & $2.58^{*}$ & 4.75 & $2.01^{*}$ & 2.18 & 0.002 \\
\hline Gen & $\mathrm{GDP}=0.0754 \times \operatorname{Gen}(-4)$ & 5.12 & 4.60 & 2.18 & 2.15 & 0.07 \\
\hline Prof & $\mathrm{GDP}=0.7757 \times \operatorname{Prof}(-2)$ & 8.50 & 4.49 & 3.92 & 2.12 & 0.48 \\
\hline Univ & $\mathrm{GDP}=0.9750 \times \operatorname{Univ}(-2)$ & 10.04 & 4.49 & 4.11 & 2.12 & 0.53 \\
\hline $\mathrm{PhD}$ & $\mathrm{GDP}=0.7669 \times \mathrm{PhD}(-2)$ & 7.96 & 4.49 & 3.51 & 2.12 & 0.44 \\
\hline Lit & $\mathrm{GDP}=0.6530 \times \operatorname{Lit}(-1)$ & 6.90 & 4.45 & 2.96 & 2.11 & 0.31 \\
\hline
\end{tabular}

* - statistically insignificant models of the influence of quantitative indicators of human capital on the economic development of the country at a significance level of $\mathrm{p}=0.05$ 
Legend:

- Emp - empirical value of the criterion modulo;

- Tab is the tabular value of the criterion at a significance level of $p=0.05$;

- GDP is the standardized value of the GDP per capita indicator;

- $\quad$ Pop -the standardized value of the population indicator;

- Birth - the standardized value of the number of births;

- Death - the standardized value of the number of deaths;

- Rep - standardized value of the population reproduction rate;

- Sick - standardized value of the indicator of the number of cases;

- Presch - standardized value of the indicator of the number of children in preschool institutions;

- Gen - the standardized value of the indicator of the number of students in day-time general education institutions;

- Prof - standardized value of the indicator of the number of students in vocational education institutions;

- Univ - the standardized value of the indicator of the number of students in universities;

- Ph.D. - the standardized value of the indicator of the number of students enrolled in the Ph.D. program;

- Lit - the standardized value of the literacy rate of the population.

All factors have a stimulating effect on economic development: their increase contributes to the growth of GRP per capita. The significant influence of factors on economic development is manifested with a lag of 1 or 2 years. The values of elasticity indicators indicate that the most significant influence is exerted by the development of cognitive skills, an increase of which by $1 \%$ leads to an increase in the GRP per capita in the next period by $2.22 \%$.

Similar regression models were constructed for quantitative indicators of human capital development (Table 3 ). The table shows the most statistically significant models of each quantitative indicator's influence on economic development from variations of linear models (without a time lag, with a lag of 1-10 periods).

The excess of the empirical values of the Fcriterion and t-criterion in modulus over the tabulated ones indicates a statistically significant influence of the considered quantitative indicators of human capital on the level of economic development of Azerbaijan, except for indicators for the number of children in preschool institutions (Presch) and the number of births (Birth). For the Presch, and Birth indicators, the empirical values of the criteria are below the table. Despite the statistical significance, the influence of quantitative indicators on economic development is less significant, confirmed by the values of elasticity indicators. For quantitative indicators, they are at the level of | $0.07-0.53 \%$ |, for qualitative | $0.58-2.22 \%$ | in the pre-crisis period and | $1.09-3.81 \%$ | during a pandemic.

Due to the priority of the influence of qualitative characteristics on the level of economic development, equation (2) for calculating the integral indicator of human capital development has got the form:

$$
Q H C=0.25 \times \operatorname{Cog}+0.12 \times S t a b+0.14 \times C r e a t+0.19 \times \text { Init }+0.17 \times D e v+0.13 \times M o b
$$

Considering the current socio-economic development conditions, the coefficients of the significance of factors of qualitative characteristics of human capital development 
were calculated based on elasticity indicators during a pandemic (Table 2).

The integral indicators of human capital development calculated according to formula
(3) have growth dynamics (Table 4) during 2017-2019, which reflects the dynamics of all particular indicators (factors).

Table 4: Values of the integral indicator of human capital development for the period 2017-2020 in the context of the region's economy of Azerbaijan

\begin{tabular}{|l|l|l|l|l|l|}
\hline \multirow{2}{*}{ Economic region } & \multicolumn{3}{|l|}{ Indicator values for the period } & Indicator \\
\cline { 2 - 6 } & $\mathbf{2 0 1 7}$ & $\mathbf{2 0 1 8}$ & $\mathbf{2 0 1 9}$ & $\mathbf{2 0 2 0}$ & \\
\hline Baku city & 3.74 & 3.78 & 3.86 & 3.74 & - \\
\hline Absheron & 3.54 & 3.60 & 3.66 & 3.57 & - \\
\hline Ganja-Gazakh & 3.41 & 3.44 & 3.47 & 3.38 & - \\
\hline Sheki-Zagatala & 3.36 & 3.38 & 3.39 & 3.30 & $\square$ \\
\hline Lankaran & 3.32 & 3.34 & 3.37 & 3.25 & $\square$ \\
\hline Guba-Khachmaz & 3.46 & 3.49 & 3.56 & 3.48 & - \\
\hline Aransky & 3.48 & 3.50 & 3.53 & 3.46 & - \\
\hline Kelbajar-Lachinsky & 3.17 & 3.19 & 3.21 & 2.97 & $\square$ \\
\hline Gorno-Shirvan & 3.40 & 3.41 & 3.44 & 3.33 & $\square$ \\
\hline Nakhchivan Autonomous Republic & 3.61 & 3.66 & 3.68 & 3.57 & $\square$ \\
\hline
\end{tabular}

In 2020, in all districts, the decrease in the integral indicator was $1.9-7.6 \%$ compared to 2019, which, judging by the dynamics of particular indicators, was due to decreased psychological stability, mobility, and adaptability.

A decline in human capital development creates additional threats to economic development in the short term (1-2 years). These threats were assessed based on the dynamics of factors of qualitative characteristics of human capital development (Table 1) and the elasticity of their influence on economic development (Table 2). An analog of the GRP indicator at the national level is the GDP indicator. Therefore, to assess the threat to economic development in the short term, the elasticity coefficients (given in Table 2) are interpreted as the percentage change in the GDP per capita indicator with an increase in the qualitative characteristics of human capital development by $1 \%$. The change in GDP per capita for 2021 under the influence of factors of human capital development's qualitative characteristics was shown in Fig. 1.

Based on the values of the factors of qualitative characteristics of human capital development for 2019 (for the factors Creat, Init, Dev, Mob) and 2020 (for the factors Cog, Stab), the percentage change in the GDP per capita indicator for 2021 was calculated. As a result of the influence of the dynamics of human capital development, it will be $3.04 \%$, which is due to a decrease in psychological stability factor according to the results of the survey for 2020 . The individual influence of this factor will lead to a decrease in the GDP per capita indicator by $14.58 \%$, which is partially offset by other indicators' growth. 


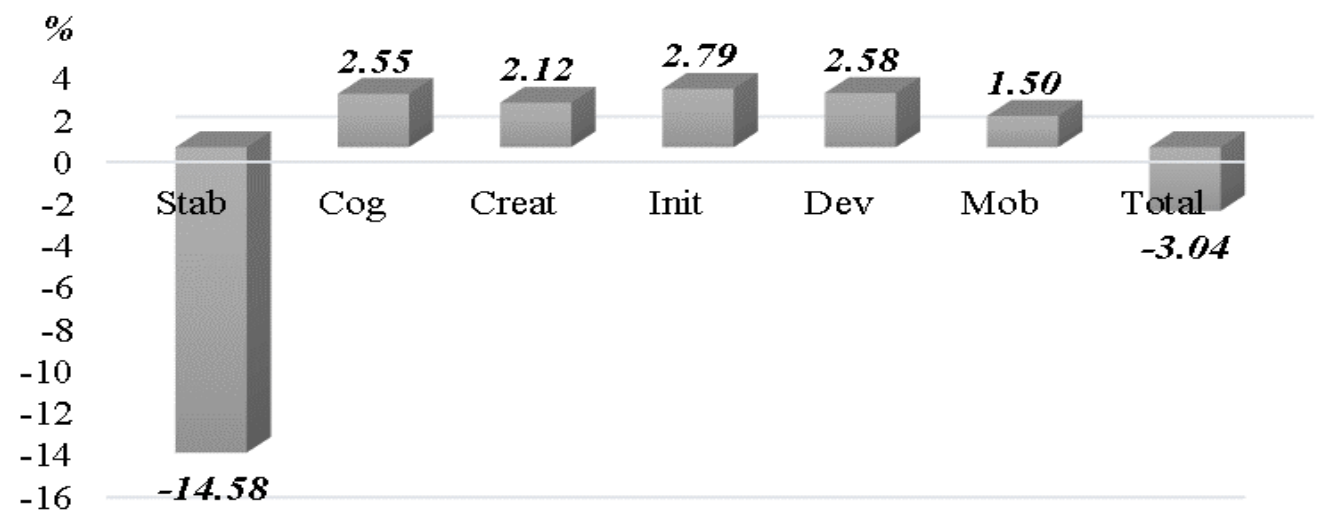

Figure 1: Change in GDP per capita in Azerbaijan for 2021 under the influence of factors of qualitative characteristics of human capital development

To calculate the change in GDP per capita for 2022 , it is necessary to predict the values of factors whose influence on economic development manifests itself with a lag of 1 year (this is a factor in developing cognitive skills and psychological stability). But forecasting under conditions of uncertainty created by the pandemic is not feasible since it will not have high accuracy. Therefore, the calculation of the total change in GDP per capita under the influence of human capital development for 2022 was not carried out. Simultaneously, it can be argued about the destabilizing effect of the factor of mobility and adaptability, a decrease in which, according to the results of the survey for 2020, will lead to a decrease in GDP per capita by $13.26 \%$. The stabilizing influence of human capital on economic development is expressed through the factor of creativity and innovative activity (GDP per capita growth by $3.26 \%$ ), initiative (by $5.42 \%$ ), and the ability to develop (by $0.8 \%$ ).

\section{DISCUSSION AND CONCLUSION}

In contrast to Lim et al. (2018; World Bank Group, (2020); Zhou et al. (2018); and Perepelkin and Perepelkina, (2018), our approach allows taking into account the national characteristics of the qualitative characteristics of human capital since it is formed based on qualitative indicators of the one country - Azerbaijan. This, in turn, most adequately and reliably takes into account the peculiarities of the mentality of the country's population, welfare, quality and safety of people's lives, the effectiveness of education and upbringing systems, achievements of science and high technologies, legal support of a market economy and free competition, innovation, from the state of intellectual, ethical, political, informational, legal, managerial, economic, medical and environmental culture in general and so on. As a result of the resulting econometric assessment of the level of human capital development, it was determined that in the context of spreading of the COVID-19 pandemic, the qualitative characteristics of human capital have a priority impact on the economic development of Azerbaijan compared to quantitative ones (population, births, cases, deaths, population reproduction rate, the number of children in preschool institutions, students in daytime general education institutions, enrolled in vocational education institutions, students in universities, the number of students enrolled in the Ph.D. program, and the literacy rate of the population), which are most often used in existing research (Lim et al., 2018; Zhou et al., 2018; Perepelkin \& Perepelkina, 2018). The country's state anti-crisis strategy should be guided precisely by these indicators of human capital development with the fastest and most painless recovery goals in the post-crisis period. In particular, the most relevant is the development of cognitive skills as a factor, the increase of which in the short term (1-2 years) can help neutralize the negative dynamics of economic development during the economic 
crisis, as well as ensure steady growth of Azerbaijan's GDP in the post-crisis period.

The advantage of the proposed approach to assessing human capital is that it allows into account the state of human capital during a humanitarian crisis. This, in turn, makes it possible to identify vulnerabilities for the development of state and corporate anti-crisis strategies, revise the importance of corporate social responsibility policies, and so on.

It should be noted that this study was conducted based on the results of the survey for the period 2017-2020. Due to the limited time series, it is not possible to study the impact of human capital quality indicators on the level of economic development of a country with a lag of more than 2 years within this study's framework. Thus, the study assesses the shortterm impact of human capital on the country's economic development.

\section{REFERENCES}

Bencsik, A., Horvath-Csikos, G., Juhasz, T., \& Csanadi, A. (2019). Healthy lifestyle and behavior of Z Generation. Journal of Eastern European and Central Asian Research, 6(2), 297-308. https://doi.org/10.15549/jeecar.v6i2.269

Campbell, S.G., \& Üngör, M. (2020). Revisiting human capital and aggregate income differences. Economic Modelling, 91, 43-64. https://doi.org/10.1016/j.econmod.2020.05. 016

Carrasco, M.A., \& Bilal, U. (2016). A sign of the times: To have or to be? Social capital or social cohesion? Social Science \& Medicine, 159, 127-131. https://doi.org/10.1016/j.socscimed.2016.05 .012

Frankovský, M., Birknerová, Z., Štefko, R., Benková, E. (2019). Implementing the Concept of Neurolinguistic Programming Related to Sustainable Human Capital Development. Sustainability, 11, 4031. https://doi.org/10.3390/su11154031

Gulaliyev, M., Muradov, R., Hajiyeva, L., Muradova, H., Aghayeva, K., \& Aliyev, E. (2019). Study of Human Capital Development, Economic Indicators and Environmental Quality. Ekoloji, 28(107),
495-503.

http://www.ekolojidergisi.com/article/study -of-human-capital-development-economicindicators-and-environmental-quality-5614

Hu, G.-G. (2021). Is knowledge spillover from human capital investment a catalyst for technological innovation? The curious case of fourth industrial revolution in BRICS economies. Technological Forecasting and Social Change, 162, 120327. https://doi.org/10.1016/j.techfore.2020.1203 27

International Monetary Fund. (2021). World Economic Outlook Reports. https://www.imf.org/en/Publications/WEO

Jaouani, A., Nikolovska, M., Milovanovitch, M., \& Nielsen, S. (2020). Policies for Human Capital Development in Azerbaijan. An ETF Torino Process Assessment. European Training Foundation. https://www.etf.europa.eu/en/publicationsand-resources/publications/trp-assessmentreports/azerbaijan2020 ? page $=4 \&$ pid $=c 198 \mathrm{e} 0 \mathrm{c} 1-\mathrm{d} 05 \mathrm{a}-4315$ a572-03af8b32ba59

Liepè, Ž. (2016). Conceptual Framework of Human Capital Systemic Assessment at Macro Level. The European Proceedings of Social \& Behavioural Sciences, 355-366. http://dx.doi.org/10.15405/epsbs.2016.11.02 .32

Lim, S.S et al. (2018). Measuring human capital: a systematic analysis of 195 countries and territories, 1990-2016. The Lancet, 392, 10154, 1217-1234.

https://doi.org/10.1016/S01406736(18)31941-X

Liu, S., \& Yang, X. (2021). Human capital externalities or consumption spillovers? The effect of high-skill human capital across low-skill labor markets. Regional Science and Urban Economics, 87, 103620. https://doi.org/10.1016/j.regsciurbeco.2020. 103620.

Lusardi, A., \& Mitchell, O.S. (2014). The Economic Importance of Financial Literacy: Theory and Evidence. J Econ Lit., 52(1), 5-44. https://doi.org/10.1257/jel.52.1.5

Megits, N., Neskorodieva, I., \& Schuster, J. (2020). Impact assessment of the COVID19 
on trade between Eastern Europe and China. Journal of Eastern European and Central Asian Research, 73), 385-399. https://doi.org/10.15549/jeecar.v7i3.579

Menke, W. (2018). Factor Analysis. Geophysical Data Analysis (Fourth Edition). New York: Academic Press, 207-222.

Naval, J., Silva, J.I., \& Vázquez-Grenno, J. (2020). Employment effects of on-the-job human capital acquisition. Labour Economics, 67, 101937.

https://doi.org/10.1016/j.labeco.2020.101937

Organisation for Economic Co-operation and Development. (2020). Tackling coronavirus (COVID-19). Contributing to a global effort. http://www.oecd.org/coronavirus/en/

Park, S.-D. (2018). The Nexus of FDI, R\&D, and Human Capital on Chinese Sustainable Development: Evidence from a Two-Step Approach. Sustainability, 106), 2063. https://doi.org/10.3390/su10062063

Perepelkin, V.A., \& Perepelkina, E.V. (2018). Analysis of human capital of Russia and China in the Context of the Mutual Competitiveness of Their Economies. Revista Espacios, 39(47), 26.

Reid, N. (2015). Statistical Sufficiency. International Encyclopedia of the Social \& Behavioral Sciences (Second Edition), 418422.

Semin, A. et al. (2020). Improving Early Warning System Indicators for Crisis Manifestations in the Russian Economy. J. Open Innov. Technol. Mark. Complex., 6, 171. https://doi.org/10.3390/joitmc6040171

Soyer, K., Ozgit, H., \& Rjoub, H. (2020). Applying an Evolutionary Growth Theory for Sustainable Economic Development: The Effect of International Students as Tourists. Sustainability, 12(418). https://doi.org/10.3390/su12010418

State Statistical Committee of the Republic of Azerbaijan. (2021). https://www.stat.gov.az/?lang=en

Stauvermann, P.J., \& Kumar, R.R. (2018). Adult Learning, Economic Growth and the Distribution of Income. Economies, 6, 11. https://doi.org/10.3390/economies6010011

Thumiki, V., Jovancai-Stakić, A., \& Al, B. (2019).
Resultant effect of crisis-driven HR strategies applied during current economic crisis in Oman: An HR manager's perspective. The European Journal of Applied Economics, 16, 77-98. https://doi.org/10.5937/EJAE15-19262

United Nations Development Programme. (2020). Human Development Data Center. http://hdr.undp.org/en/data

United Nations. (2021). Sustainable Development Goals.

https://www.un.org/sustainabledevelopmen $\mathrm{t} /$ sustainable-development-goals/

Williams, A. (2020, October 1). EBRD revises down economic forecasts amid continuing coronavirus uncertainty. European Bank for Reconstruction and Development. https://www.ebrd.com/news/2020/ebrdrevises-down-economic-forecasts-amidcontinuing-coronavirusuncertainty.html\#: :text=The\%20EBRD\%20i s\%20now\%20forecasting,4.8\%20per\%20cent\% 20in\%202021.

World Bank Group. (2020). Human Capital Project.

https://www.worldbank.org/en/publication/ human-capital

Wright, P.M. (2020). Rediscovering the "Human" in strategic human capital. Human Resource Management Review, 100781. https://doi.org/10.1016/j.hrmr.2020.100781

Yasmin, T., El Refae, G. A., \& Eletter, S. (2019). Sectoral productivity in Hungarian economy: an input-output linkages approach. Journal of Eastern European and Central Asian Research, 6(2), 344-355. https://doi.org/10.15549/jeecar.v6i2.318

Zhou, G., Gong, K., Luo, S., \& Xu, G. (2018). Inclusive Finance, Human Capital and Regional Economic Growth in China. Sustainability, 10, 1194. https://doi.org/10.3390/su10041194 